NEW EVIDENCE ON REGIONAL INEQUALITY IN IBERIA (1900-2000): A GEOGRAPHICAL APPROACH

\begin{abstract}
This paper presents new evidence on the evolution of regional inequality in Iberia from 1900 to 2000 from a geographical perspective. To do so we introduce a new historical dataset of regional GDPs for Spanish NUTS III and Portuguese Historical Districts (HD), synthetic indices of regional inequality and different measures of spatial correlation across regional pc GDPs. The results show that the Portuguese and Spanish national economic integration processes initially led to the economic specialization across Iberian regions promoting the divergence in terms of their regional pc GDPs. Notwithstanding, ulterior advances in the integration of national markets and the subsequent first stages in the process of adhesion of these two national economies into the UE coexisted with a progressive reduction in Iberian regional inequality.
\end{abstract}

Keywords: Iberia; Regional Inequality; Economic Geography, Border Regions.

JEL Codes: N93; N94; R11

\title{
Authors and acknowledgements
}

Daniel A. Tirado Fabregat is associate professor of Economic History at the Universitat de Valencia, Spain. [daniel.tirado@uv.es, Departament d'Anàlisi Econòmica, Av Tarongers s/n, 46021, València, Spain]. Marc Badia-Miró is lecturer of Economic History at the Universitat de Barcelona, Spain. [mbadia@ub.edu, Departament d'Història i Institucions Econòmiques, Facultat d'Economia i Empresa, Av. Diagonal 690, 08034, Barcelona, Spain]. 
We acknowledge the financial support received from XREPP and ESF Research Network-GLOBALEURONET, from the research projects ECO2009-13331-C02-02, ECO2012-39169-C03-02 and ECO2012-39169-C03-03 financed by the Innovation and Science Ministry of Spain and from the Catalan Government through the research action 2009SGR153 (Antoni de Campany Centre of Economy and Economic History). The paper was presented at the conference L'ús dels SIG en l'estudi de la integració europea (1870 - 2010), Universitat de Lleida and at the III Encuentro de la Asociación Española de Historia Económica, Barcelona. We would like to thank several participants for their comments, in particular J. Martí-Henneberg, F. Goerlich, J. Martínez-Galarraga, J. M. Arauzo-Carod, E. Felice and L. German. Comments by Pedro Lains, Alfonso DíezMinguela and Alfonso Herranz have been also of great help. We also acknowledge the comments done by the referees. The usual disclaimer applies. 
NEW EVIDENCE ON REGIONAL INEQUALITY IN IBERIA (1900-2000): A GEOGRAPHICAL APPROACH

\section{Introduction}

This paper presents new evidence on the evolution of regional inequality in Iberia from 1900 to 2000 from a geographical perspective. In particular, we are interested in the geographical description of economic inequality in Spain and Portugal during the process of economic integration of their national markets, as well as other economic changes, from mid- $20^{\text {th }}$ century onwards. It was then, when both economies started a process of increasing integration into the European and the international economy. This integration into the European economic area was reinforced during the last 30 years of the $20^{\text {th }}$ century, with the diffusion of many preferential trade agreements among Spain, Portugal and the EEC (in 1970 and 1972 respectively), reaching its peak with the formal accession of both economies to the EEC in 1986, that ultimately led to the whole integration of the Iberian economy. ${ }^{1}$ Within this context, it seems interesting to analyze whether regional economic inequality has followed a differentiated geographical pattern, as the one followed by the two economies when they remained highly protected and, especially, if we observe a common geographical pattern parallel to the process of mutual economic integration, and also during the integration into the European economy.

In order to contextualize these geographical patterns in the levels of development of the Iberian regions, we first offer a brief abstract of the historical evolution of the integration process of the Spanish and Portuguese national markets since the beginning of the $20^{\text {th }}$ century onwards, as well as the main milestones in the process of integration of these economies into the European market. 
Then, we show a new database of regional GDP pc for Spain and Portugal. This database contains retrospective estimations for the Spanish NUTSIII and for the Portuguese Historical Regions (HD), in pesetas and escudos, for all the decennial benchmarks between 1900 and 2000. Moreover, to obtain homogenized values for all the regions, we have converted national currencies in 1990 International Geary-Khamis US dollars, from (Maddison 2010). The new dataset on Iberian historical regional GDP per capita, that consents for the first time the integration of long term data estimated for this two neighbouring countries, has been constructed following the methodology proposed by Geary and Stark (2002) and the refinement suggested by Crafts (2005). This methodology has recently been extensively used by the researchers participating in the European Science Foundation Research Network (GLOBALEURONET) for the estimation and analysis of the long-term patterns of regional economic inequality in some European individual countries such as Belgium (Buyst 2010) or Italy (Felice 2011).

With this information, we also show a first approximation of the evolution of the regional economic inequality in the area, and analyze the presence of some regional patterns. Finally, we test this hypothesis through spatial econometric techniques and obtain some indices of spatial autocorrelation at a regional level of GDP pc, as well as their temporal evolution.

The results show that Portuguese and Spanish national integration processes initially promoted the economic divergence of Iberian regions, in terms of their regional pc GDPs. Notwithstanding, ulterior advances in the integration of national markets and the subsequent first stages in the process of adhesion of these two national economies into the UE coexisted with a progressive reduction in Iberian regional inequality. Therefore, Iberian regional inequality depicts a long term U-shaped evolution. Furthermore, Iberian regional inequality shows a significant geographical pattern. The poorest regions cluster 
in inland territories of the south and west, with regions belonging to this cluster located on the two sides of the political border. In contrast, richest regions cluster along the coasts and in the north-east corner of the Iberian Peninsula. The data show that this pattern was well established in the middle of the $20^{\text {th }}$ century, before the reciprocal openness of national markets in the 1980s. In this respect, the adhesion of both economies to the UE in 1986 seems to have just caused an ulterior deepening in this historical pattern.

\section{Milestones in Spanish and Portuguese market integration}

The integration of the Portuguese domestic market occurred at a last stage compared with other experiences (Italy, France, USA or even Spain). In fact, only the improvement of the transport network during the last third of the $19^{\text {th }}$ century, which can be exemplified with the expansion of the railway network, made possible the reduction of the higher transport costs existing among the main urban areas (Porto and Lisbon) and the rural inner and southern regions. ${ }^{2}$ Nevertheless, the effects of this expansion must be considered with some caution. In fact, the construction of this infrastructure did not follow the logic of the national market integration. Their objective was the connection with the external borders. It is also worth remembering that the major urban markets, Porto and Lisbon, were supplied by sea. A huge part of short distance transport was done by traditional ways and, therefore, transport costs remained higher. For the whole $19^{\text {th }}$ century, we can describe Portugal as a country with a fragmented economy, however, the extension of the railroad made available the link of the agricultural production of the inner regions to the international markets, through the ports of the coast. This process was also reinforced with the connection of the main cities (connection Lisbon - Porto). The result was a strong boost of the domestic trade, powered by a protectionist turn of the Portuguese trade policy at the end of the $19^{\text {th }}$ century. ${ }^{3}$ 
During the first decades of the $20^{\text {th }}$ century, there was a consolidation of the regional networks. ${ }^{4}$ However, the construction and the improvement of roads could be described as a late process in European terms. Prior to the spread of railways, highways and roads were bad, channels were almost non-existent and navigable rivers, all transversals, only responded to the logic of short distance transport. Although the first highways appeared just before World War II and the roads between major cities were built during the 1950s and 1960s, the real expansion of those infrastructures would not arrive until the 1980s.

With respect to the integration of the Portuguese economy into the international markets, it should be noted that after the liberal period, which extends from mid-19 ${ }^{\text {th }}$ century until the 1880 s, the Portuguese trade policy was characterized by a high degree of protection to the domestic industrial and agrarian production. ${ }^{5}$ This shift would have their roots in the crisis of the end of the century and was reinforced with the 1886 tariff. Since then and except for the timid attempt of trade liberalization initiated at the end of the 1950 's, the main feature of the Portuguese trade policy was the higher protection of the domestic production. However, since the early 1960s, the country started a process of a gradual economic liberalization (founding member of EFTA in 1960, signing preferential treaties with the EEC in 1972, or, above all, the formal integration into the EEC in 1986). ${ }^{6}$

From a long-term perspective, Spanish internal market integration received a strong push in mid- $19^{\text {th }}$ century. In fact, prior to there, Spanish regions had relatively independent economies. ${ }^{7}$ The presence of barriers to interregional trade and the movement of capital and labour were ubiquitous: local tariffs and regulations on domestic commerce were widespread; weights and measures differed across regions; transport costs were very high due to low public investment in transport infrastructures and the particular geography of Spain, which lacked an extensive water transport system; 
economic information moved slowly across regions; the banking system was underdeveloped; and many regions had their own currencies (although all currencies were based on a bi-metallic monetary system).

Both market liberalization and transport improvements, particularly the completion of Spain's railways network, induced the creation of a national market for most important commodities during the second half of the $19^{\text {th }}$ century and this process of national market integration progressed steadily until the Spanish Civil War. ${ }^{8}$ Then, the Spanish Civil War and the first years of Franco's regime put a brake on the national economic integration. The regulation of markets for goods and factors of production and government control of prices and quantities in final goods, intermediates, energy, capital markets and wages reduced the mobility of factors and resources.

The economic liberalisation and stabilisation measures introduced at the end of the 1950s favoured the transition of the Spanish economy toward a new phase of economic development. This period was characterised, among other elements, by high aggregate growth rates of production and by the lead taken by the industrial sector in the country's economic activity. New investments in infrastructures such as roads, railways, communication networks and energy supply and distribution led to further reductions in internal transport costs. The crisis of the 1970s, which in the case of Spain stretched well into the 1980s, put a brake on these upward trends, and high average GDP growth rates were not recorded again until the final years of the $20^{\text {th }}$ century. During the last fifteen years of the $20^{\text {th }}$ century a new wave of investment in infrastructure helped to reduce further transport cost across Spanish regions through the implementation of huge investment programs in freeways, high-speed railway and telecommunications.

The main patterns of integration of the Spanish economy into the global economy are very similar to those described for Portugal. Although the liberal reforms established 
in the mid $-19^{\text {th }}$ century ended the main prohibitions on foreign trade and favoured the free movement of capital and labour across Spain's borders, Spanish foreign trade policy also took a protectionist turn in the late 1880 s which extended well until the end of the Primo de Rivera's dictatorship in 1929. The Franco regime adoption of an autarkic policy during the 1940s implied the total isolation of the Spanish economy from the international market. Foreign trade and international capital movements during these years reached their lowest levels in contemporary Spanish economic history.

Nevertheless, the liberalizing policies of the 1950s also affected the Spanish integration into the international economy. Although at a slow pace, Spain started to recover its position in the international markets. Spain's membership in international organisations such as GATT, World Bank and IMF, and the liberal winds regarding the regulation of international commodity and capital movements, marked the starting point for a new wave of growth in the movement of goods, capital and labour across Spanish borders. In any case, the level of integration reached by the Spanish markets for goods and capital during this period cannot be considered those of a truly open economy. Notwithstanding, from the years of the Democratic Transition, Spain experienced major advances in the integration in international markets. In this respect, the signature of the preferential agreement with the EEC in 1970 and overall, the ascension of Spain to the CEE in 1986 acted as big institutional reforms that changed the framework in which the specialization of Spanish regions took place. Finally, considering the economic relations between Spain and Portugal, the milestone was the signing of Spain's trade agreement with EFTA in 1980 (as Portugal was a member, the Hispano-Portuguese trade recorded since then, a sharp reduction in duties) and the adhesion of these two economies to the EEC in 1986. 


\section{A New Estimation of pc GDPs for Iberian regions}

The database of the study includes data of GDP pc for the Spanish NUTS III, with the exception of Canarian provinces and the Portuguese historical districts (HD), for all the decennial benchmarks between 1900 and 2000. For the Spanish regions, the figures between 1900 and 1930 come from Rosés et al. (2010). From 1930 on, the data have been collected from different well known sources such as Alcaide (2003) for the years 19401950, BBV (1999) for the years 1960-1990 and FUNCAS (2004) for the year 2000. Regional population figures have been collected from Spanish Population Censuses.

The Portuguese regional GDP per capita data among 1900 and 1950 comes from Badia-Miró et al. (2012). From 1950 onwards we consider official sources as Abreu (1969), an official publication from INE, which provides data for the Historical Divisions (HD) for 1953 and 1963, da Conceição (1975) for 1970 data and Instituto Nacional de Estadística (1988) for 1980. For 1995 onwards, EUROSTAT provides regional data based in NUTS II and NUTS III. The population data comes from Nunes (1989) and EUROSTAT.

Due to the fact that NUTS-III (from 1990 onwards) and the Historical Division (1900 - 1980) haven't got a direct correspondence, we have obtained new regional GDP data for the historical regions for the whole period as follows. To transform NUTS-III GDP figures into HD GDP figures, we have distributed each NUTS-III GDP across its main municipalities in accordance to each municipality population share. After doing that, we assigned the GDP of each municipality to the HD where this municipality was located in the past. For a more detailed description of the procedure followed for the transformation, see Tirado and Badia (2012).

Lastly, in order to homogenize Portuguese and Spanish regional data, we have considered, for each year, the percentage of total GDP corresponding to each region, and 
we have recalculated it considering the Spanish and the Portuguese GDP, in 1990 International Geary-Khamis US dollars, from Maddison (2010). Regional GDP pc of Iberian regions is obtained from these results.

\section{Long term paths of regional income inequality in Iberia}

In this section, we take a first look at the evolution of Iberian regional inequality. Figure 1 illustrates the long-term evolution of two inequality indices for Iberian regions between 1900 and 2000.

As it can be seen, the first stages of the integration of Spanish and Portuguese domestic markets witnessed a trend of increasing regional income inequality - that is, between 1900 and $1920 .{ }^{9}$ After that, regional inequality was gradually reduced, only to be interrupted during the years of explosive growth in the 1950s and 1960s. So, it can be pointed out that, over the long term, regional income inequality followed a U-shaped pattern, with a growth in inequality between 1900 and 1920 followed by a long phase of declining regional inequalities that lasted until the end of the century.

Figure 1 - Indices of Regional GDP pc Inequality in Iberia

Source - (Rosés, Tirado and Martinez-Galarraga 2010) and this text for Spanish NUTS3 and this text for Portuguese HD.

Figure 2 complete the overview of this long run evolution of the spatial distribution of the economy, considering the dispersion among the higher and the lower quintile. The higher levels of dispersion among the richer and the poorer regions were reached in the 1920s. Besides, the ratio also shows a slow increase until the 1950s and 
the 1960s. The drivers of the increase in regional income inequality varied between the pre-1920 period and the subsequent. In the first period, the increase was related with the fall of the relative GDP pc in the lower quintile, that is, the increase of the distance among the poorer regions and the Iberian average. In the second period, the relative growth of the poorer regions was not enough to reduce regional inequality due to a higher growth in the richer regions. From this year onwards, the dispersion sharply decreased to the lower levels of the period under analysis. The reason behind this movement was the existence of a double convergence to the Iberian average from both, the richer and the poorer provinces, which strongly reduced the gap.

Figure 2 - Dispersion of the Regional GDP pc Inequality in Iberia Source - (Rosés, Tirado and Martinez-Galarraga 2010) and this text for Spanish NUTS3 and this text for Portuguese HD.

However, as we have pointed out, the objective of this paper is to analyze the possible existence of geographical patterns in the spatial distribution of regional GDP pc levels. In this sense, maps 1 to 6 can provide a first approach to the evolution of the geography of the regional economic inequality in Iberia, in the long run. In particular, the gray scale used includes the per capita income levels relative to the average of the whole region, with darker shades highlighting those regions in the first quintile of the regional distribution. By contrast, white would be for the poorest regions, which occupied the bottom quintile of the distribution. ${ }^{10}$

Map 1 - GDP pc Iberia, 1900 (1990 GK \$US in miles) 
The map corresponding to 1900 aims to an Iberian economy with a moderate level of inequality (the abundance of gray represents the concentration of many regions at intermediate levels of income and a geography of relative wealth-poverty not well defined (poor and rich regions were distant, coast-inner regions, north-south).

Map 2 - GDP pc Iberia, 1920 (1990 GK \$USin miles )

Map 3 - GDP pc Iberia, 1940 (1990 GK \$US in miles)

The geographic picture portrayed for 1900 changes gradually throughout the $20^{\text {th }}$ century. A specific pattern of regional economic inequality in Iberia seems to arise with some relevant aspects. First, it should be noted from this map of inequality the formation of some clusters of rich and poor regions, with a strong geographical pattern. The income levels of regions were not randomly distributed in the territory, as rich and poor regions seem to clusters in groups. Second, these clusters have a specific location which remains quite stable and consolidates over time. Regions in the Northeast quadrant of the peninsula and the coastal regions exhibit a higher per capita income levels than those located in inland areas, particularly in the West and South of the Peninsula. Third, low levels of income are concentrated in a group of regions located on both sides of the border between Spain and Portugal. The formation of this group has their roots in the first half of the $20^{\text {th }}$ century, and seems to be consolidated in recent benchmarks, in parallel to the process of integration of both economies into the European economy.

Map 4 - GDP pc Iberia, 1960 (1990 GK \$US in miles) 
Map 5 - GDP pc Iberia, 1980 (1990 GK \$USin miles)

Map 6 - GDP pc Iberia, 2000 (1990 GK \$USin miles)

The evidence here described gives a set of stylized facts about the geographical patterns of regional inequality in Iberia that deserve to be checked by statistical analysis. Thereafter, we consider some tools of spatial statistics in order to go deep and sharpen into these hypotheses, derived from direct observation on the evidence described in this section.

\section{Spatial Correlation Analysis}

As we have said, we are interested in analyzing the statistical significance of the apparent geographical patterns of regional income inequality described previously. In order to do so, in this section we make use of some spatial statistics techniques. Particularly, we have computed the Moran's I coefficient for the Portuguese historical districts, the Spanish provinces and for the whole Iberia. This coefficient tests the existence of a statistical relationship among the estimated regional GDP pc for any region and the level of GDP pc in the neighboring areas. That is, we are going to analyze the possible existence of a spatial pattern of regional GDP pc in our samples. When two or more regions are statistically spatially correlated, we assert that the variable observed in one region is strongly linked with the value of this variable in the in neighboring regions. On the contrary, when the variable is randomly distributed, the values in each region are independent of what is happening in their neighboring regions. To do that we compute Moran's I as: 


$$
I=\frac{z^{\prime} W z}{z^{\prime} Z}
$$

Where $\mathrm{W}$ is the distance matrix among contiguous regions and $\mathrm{z}$ is the variable under analysis.

In this study, we have calculated this index considering a distance matrix, where the cells are one for contiguous provinces and zero in other cases. Therefore, it's an analysis of spatial autocorrelation based in a contacts matrix. ${ }^{11}$ The values reached by this coefficient and their temporal evolution could be observed in Figure 2.

Moran's I coefficient for the Portuguese regions was very low, showing negative values for some benchmarks, although with a very low significance level. Nevertheless, from 1950 onwards, the values turn to positive, although the significance remained low. The Spanish case shows a similar trend, although the starting levels were different. Lower values of this ratio are recorded during the first third of the $20^{\text {th }}$ century. From 1940 onwards, the series showed a long-term trend of growth in the calculated Moran's I coefficient, which is to say in the presence of a significant relationship between each region regional income levels and the one observed in its neighboring regions. Moreover, the values reached by the coefficient are always statistically significant.

Figure 3 - Spatial correlation coefficient (I-Moran) Portugal, Spain and Iberia, 1900 2000.

Notwithstanding, the most interesting fact showed figure 2 is the level and evolution of the Moran's I coefficient calculated for the whole Iberia. First, we observe that for the period prior to the 1940s, the values reached by Moran's I coefficient for Iberia show the existence of a highly significant spatial correlation among regional pc GDPs. In fact, the 
values reached for this statistic in the sample of Iberia are higher than those calculated independently for each country. This would indicate that the Iberian geographical pattern reflects better the geography of the economic inequality than those derived of the isolate consideration of Spanish or Portuguese economies. This situation changed during the years of the take-off, in the decades of 1950s and 1960s (in a context of highly protected economies). However, from the 1960s onwards, Moran's I of Iberia increases, reaching highly significant values. Furthermore, this growth occurred in parallel with the convergence among the values recorded for this Index in Spain and for the whole Iberia. This growing degree of spatial autocorrelation across pc GDPs of Iberian regions could be related to the strengthening of the Iberian economy along the process of Spanish and Portuguese international economic integration.

However, it would be interesting to analyze which regions determine the overall significance and the evolution of Moran's I statistic, and determine if these spatial relationships exist between the richest regions of the peninsula or between groups of poor regions. Besides, it would also be very interesting to determine if the spatial correlation occurs only among regions belonging to same state or there are groups of regions with high correlation in their levels of income which are located in both sides of the political Hispano-Portuguese border.

With the objective of going further in the understanding of these elements, we present new evidence in Maps 7 to 12. In these maps, following the approach of Anselin et al. (2004), we introduce statistical data on local Moran's I index, which will give us specific information about which regions have some spatial correlation among levels of GDP, and whether that relationship is between groups of regions with low or high-income (above or below average). ${ }^{12}$

The colors of the maps show: 
- Blue: high correlation among regions with low level of GDP pc.

- Red: high correlation among regions with high level of GDP pc.

- Light red: high correlation among regions with high level and low level of GDP pc.

- Light blue: high correlation among regions with low level and high level of GDP pc.

From the information provided on the maps, we highlight the following aspects. First, the spatial correlation between the levels of regional per capita income is significant in a huge number of cases. Moreover, this correlation only affected a relatively small number of regions at the beginning of the $20^{\text {th }}$ century. Nevertheless, as the century advances, this significant correlation spreads to more and more regions. ${ }^{13}$ That is, in correspondence with the growing evolution of Global Moran's I, the presence of a significant spatial correlation among pc GDPs affects to a growing number of regions.

Second, the information contained in these maps shows the gradual generation of a regional economic inequality map in Iberia, placing a cluster of rich regions in the Northeast quadrant of the Peninsula and another group of poor territories in the inland regions of the South and the West.

Map 7- LISA Map of Spatial Correlation Significance. 1900

Considering this, we derive two further assessments. First, the regions where the capital cities of the two states are located (Madrid and Lisbon) are not members of any of these clusters. Madrid and Lisbon GDP pc are higher than the levels of their neighboring regions. Therefore, we could argue for the existence of a capital effect with no diffusion to the closest regions. 
Map 8 - LISA Map of Spatial Correlation Significance. 1920

Second, it could also be observed that the cluster of relatively poor regions, where there are significant spatial correlations in income level, includes regions belonging to the two states that comprise Iberia. Moreover, it can be noted that this fact appears already in the beginning of the $20^{\text {th }}$ century, and that it was well established in the $1960 \mathrm{~s}$. In this sense, the growing integration of the two Iberian economies since 1970s, and especially since 1986, seems to have reinforced a spatial relationship between income levels of regions on either side of the border that it was already present in the first half of the 20th century.

Map 9 - LISA Map of Spatial Correlation Significance. 1940

Map 10 - LISA Map of Spatial Correlation Significance. 1960

Map 11 - LISA Map of Spatial Correlation Significance. 1980

Map 12 - LISA Map of Spatial Correlation Significance. 2000

\section{Conclusions and research agenda}

This paper studied the evolution of regional inequality in Iberia from 1900 to 2000 from a geographical perspective. For this purpose we have introduced a novel historical dataset of regional GDP for Spanish NUTS III and Portuguese Historical Divisions, synthetic indices of regional inequality and different measures of spatial correlation across regional 
pc GDPs. Our results show that the Portuguese and Spanish national economic integration processes initially favored the economic specialization across Iberian regions fostering the divergence in terms of their regional pc GDPs. Notwithstanding, ulterior advances in the integration of national markets and the subsequent first stages in the process of adhesion of these two national economies into the UE coexisted with a progressive reduction in Iberian regional inequality. Thus, Iberian regional inequality depicts a long term U-shaped evolution.

Nevertheless, at the same time, Iberian regional inequality followed a significant geographical pattern. The poorest regions cluster in inland territories of the south and west, with regions belonging to this cluster located on the political border. On the contrary, richest regions cluster along the coasts, especially in the north-east corner of the Iberian Peninsula. Besides, the data show that this pattern was well established in the mid $20^{\text {th }}$ century. In fact, our results show that in 1920 it was already possible to identify the main axis of current Iberian economic development, the capital cities (Lisbon and Madrid), the north-east Mediterranean corner, the Basque Country and the regions in between these two, following the Ebro Valley. In any case, it seems important to note that the geography of Iberian development was defined before the reciprocal openness of national markets in the 1980s. So, the adhesion of both economies to the UE in 1986 seems to have just caused an ulterior deepening in this historical pattern.

This new evidence arise new questions for the future. First, it could be interesting to deepen into the main drivers of the regional economic inequality in Iberia. In this regard, a recent work by Legallo and Karamiakis (2011) combines traditional shift share analysis with spatial econometric analysis. This work tries to identify whether spatial relationships in terms of regional GDP pc are due to the similarities in the production structures of adjacent regions or due to those existing in the neighboring regions average 
productivity levels or in a combination of both effects. The findings of this exercise could take us one step forward in the understanding the determinants of regional inequality in the long term, by identifying the role played by differences in relative factor endowments or the presence of market size effects under a long-term process of increasing economic integration, at a supranational level.

Second, it also could be interesting to use the Iberian economy historical experience in order to analyze the presence and evolution of border effects, in terms of regional GDP pc. This historical episode could provide us with some insights about the evolution of the magnitude of this effect after the disappearance of those factors that transform a political border into an economic border, such as the reduction of transport costs, the disappearance of tariff barriers or the full liberalization of capital and migration flows. This kind of analysis would provide new evidence to the controversy about the economic significance of political boundaries or, from another perspective, make a significant contribution to the debate on the endogeneity of political boundaries. ${ }^{1413}$ In this way, the evidence showed in this paper suggests that the political and institutional borders between the two Iberian states have not prevented the existence of intense economic relations between border regions before and after the recent process of European economic integration.

Summing up, the results of the present and the future research on the historical patterns of regional income inequality in Iberia may serve to take some light to the current debates on the effects of the ongoing process of EU integration.

\section{References}

Abreu, A. T. d. 1969. O Crescimento Regional Em Portugal. Análise Da Sua Distribuçao. Lisboa, Fundado Calouste Gulbenkian/Centro de Estudos de Economía Agraria. 
Afonso, Ó., and Á. Aguiar. 2004. Comércio Externo e Crescimento Da Economia Portuguesa No Século XX. FEP Working Papers. Universidade Do Porto, Faculdade De Economia Do Porto. http://ideas.repec.org/p/por/fepwps/146.html.

Alcaide Inchausti, J. 2003. Evolución Económica De Las Regiones y Las Provincias Españolas En El Siglo XX. Fundación BBVA.

Alegria, M. F. 1988. Análise Geográfica Do Transporte De Mercadorias Nos Caminhosde-ferro Portugueses No Século XIX. Análise Social 24 (101/102): 769-803.

Anselin, L., R. Florax, and S. Rey (eds.). 2004. Advances in Spatial Econometrics. Methodology, Tools and Applications. Berlin: Springer-Verlag.

Badia-Miró, M., Guilera, J., and Lains, P. 2012. Regional Incomes in Portugal: Industrialisation, Integration and Inequality, 1890-1980. Revista de Historia Económica - Journal of Iberian and Latin American Economic History, 30 (2), 225-244. doi:10.1017/S0212610912000080

Buyst, E. 2010. Continuity and Change in regional disparities in Belgium during the twentieth century. Journal of Historical Geography doi:10.1016/j.jhg.2010.11.005.

da Conceição, M. M. Lobo. 1975. Considerações Sobre o Projecto 'Repartição Regional Do Produto, Ensaio Para 1970'. Estudos 48. Instituto Nacional de Estatística. Portugal. Corkill, D. 1999. The Development of the Portuguese Economy: a Case of Europeanization. Routledge.

Felice, E. 2011. Regional value added in Italy, 1891-2001, and the foundation of a longterm picture. Economic History Review 64(3): 929-950.

Herranz, A. 2008. Infraestructuras y crecimiento económico en España (1850-1935). Fundación de los ferrocarriles españoles, Madrid. Instituto Nacional de Estadística. 1988. Portugal. Regionaliziçao. Vol. 1. Series Estudios 
60.

Lains, P. 2003. Catching up to the European Core: Portuguese Economic Growth, 19101990. Explorations in Economic History 40 (4): 369-386.

Lains, P. 2007. Growth in a Protected Environment: Portugal, 1850-1950. In Research in Economic History, 24:119-160. Bingley: Emerald (MCB UP).

Maddison, A. 2010. Historical Statistics. PIB and Population Data. http://www.ggdc.net/maddison/Historical_Statistics/horizontal-file_02-2010.xls

Martínez-Galarraga, J., Rosés, J. R. and Tirado, D. A. 2013. Long-Term Patterns of Regional Income Inequality in Spain, 1860-2000, Regional Studies, DOI:10.1080/00343404.2013.783692

Matos, A. M. Cardoso de. 1991. A Indústria No Distrito De Évora, 1836-90. Análise Social 26 (112/113): 561-581.

Nunes, A. B. Ferreira Macias. 1989. Populaçao Activa e Actividade Economica Em Portugal Dos Finais Do Século XIX a Actualidade. Uma Contribuiçao Para o Estudo Do Crescimiento Económico Portugués. Instituto superior de economia da Universidade Tecnica de Lisboa.

Pereira, Á. Santos, and P. Lains. 2011. From an Agrarian Society to a Knowledge Economy? The Rising Importance of Education to the Portuguese Economy, 1950-2009'. In Higher Education in Portugal 1974-2009, G. Neave and A. Amaral (ed.), 109-134. Dordrecht: Springer Netherlands.

Prados de la Escosura, L., and J. R. Rosés. 2009. The Sources of Long-Run Growth in Spain, 1850-2000. The Journal of Economic History 69 (4): 1063-1091.

Rosés, J. R., J. Martínez-Galarraga, and D. A. Tirado Fabregat. 2010. The Upswing of Regional Income Inequality in Spain (1860-1930). Explorations in Economic History 47: 244-257. 
da Silva Lopes, J. 1996. A Economia Portuguesa Desde 1960. Vol. 36. Lisboa: Gradiva. Silveira, L. E. da, D. Alves, N. Miguel Lima, A. Alcântara, and J. Puig. 2011. Population and Railways in Portugal, 1801-1930. Journal of Interdisciplinary History 42 (1): 29-52. Tirado, D. A., and M. Badia-Miró. 2012. Economic integration and regional inequality in Iberia (1900-2000): a geographical approach. Working Papers in Economic History. Universidad Carlos III de Madrid. Departamento de Historia Económica e Instituciones, $12(03)$.

Wolf, N. 2005. Path Dependent Border Effects: the Case of Poland's Reunification (19181939). Explorations in Economic History 42 (3): 414-43.

Wolf, N. 2008. Was Germany ever United? Evidence from Intra- and International Trade, 1885-1933. Journal of Economic History 69 (3): 846-881.

${ }^{1}$ A first step for the economic integration among Spain and Portugal took place in 1980, with the trade agreement among Spain and the EFTA. Due to the membership of Portugal into the EFTA, the trade among Spain and Portugal was reinforced by the strong reduction in the duty levels.

${ }^{2}$ In this fragmented economies, a traditional manufacture have survived, which were not able to compete with the products arrived from Lisbon and Porto (Matos 1991).

3 (Alegria 1988).

${ }^{4}$ (Silveira et al. 2011).

${ }^{5}$ See da (Silva Lopes 1996) and (Lains 2003).

${ }^{6}$ (Corkill 1999), (Afonso and Aguiar 2004) and (Pereira and Lains 2011).

${ }^{7}$ A broad description of the process of national market integration in Spain could be read in (Roses et al. 2010).

${ }^{8}$ An exhaustive analysis of the impact of railways construction in the Spanish market integration could be read in (Herranz 2008).

${ }^{9}$ Rosés et al. (2010) date the beginning of this process of growth of regional inequality in Spain back to the second half of the 19th century. 
${ }^{10}$ Quintiles were obtained considering the whole sample.

${ }^{11}$ A description of the main spatial statistics methods could be read in Anselin et al. (2004).

${ }^{12}$ We have used GeoDa to obtain Map 7 to Map 12.

13 The exception is observed in the map corresponding to 1980. To explain this it could be argued that, in this case, the oil shock of the 1970s, with a strong sector component, had an asymmetric impact in the Iberian regions, which in the short term changed the relative ranking of some of the regions. However, in the long run, the main geographical trends in terms of relative income and spatial correlations reappear on the 2000 map.

${ }^{14}$ About this topic see (Wolf 2005, 2008). 